\title{
Diabetes Mellitus and Tuberculosis Comorbidity and Associated Factors Among Bale Zone Health Institutions, Southeast Ethiopia
}

This article was published in the following Dove Press journal:

Diabetes, Metabolic Syndrome and Obesity: Targets and Therapy

\author{
Habtamu Gezahegn (D)' \\ Mohammed Ibrahim ${ }^{2}$ \\ Elias Mulat $\mathbb{D}^{2}$
}

'Madda Walabu University Goba Referral Hospital, School of Medicine, Medical Physiology Unit, Bale Robe, Ethiopia; ${ }^{2}$ Jimma University, Institute of Health, Faculty of Medical Sciences, Department of Biomedical Sciences, Jimma, Ethiopia

Correspondence: Habtamu Gezahegn Email habgez47@gmail.com
Background: Globally, tuberculosis and diabetes mellitus co-morbidity is higher than tuberculosis and human immunodeficiency virus comorbidity. Considering this, the World Health Organization and the International Union against tuberculosis and lung disease recommend bidirectional screening of the two diseases. However, in Ethiopia, bi-directional screening has not been started yet.

Objective: The objective of this study was to assess the prevalence of diabetes mellitus and tuberculosis comorbidity and its predictors among adult tuberculosis patients in Bale Zone Health Institutions, Southeastern Ethiopia.

Materials and Methods: Institutional-based cross-sectional study carried out using interviewer administered questionnaire, registration review, anthropometric and blood glucose level measurement from March, 30, 2019 to April, 30, 2019. Three hundred twenty-one tuberculosis patients were selected from tuberculosis registration log book using lottery methods. The collected data were checked for completeness, coded and entered in to EpiData3.0.2 and exported to SPSS version 20. Independent variables that had p value less 0.25 were used as candidates for multiple logistic regressions to control confounders. Variables that had significant association were identified by calculating odds ratio, with $95 \%$ confidence interval, and $\mathrm{p}$ value less than 0.05 used to declare statistical significance.

Results: Diabetes mellitus and tuberculosis comorbidity among adult tuberculosis patients was $5.1 \%$ (95\% CI: $2.7 \%, 7.5 \%$ ). Age with $\geq 50$ years ( $\mathrm{AOR}=3.98,95 \% \mathrm{CI}: 1.13,14.36)$, having extra pulmonary tuberculosis $(\mathrm{AOR}=3.31,95 \% \mathrm{CI}: 1.16,9.44)$ and being females $(\mathrm{AOR}=3.8,95 \% \mathrm{CI}$ : $1.17,12.33$ ) were significantly associated with the comorbidity of the two diseases.

Conclusion and Recommendation: The prevalence of diabetes mellitus and tuberculosis comorbidity was high. Female tuberculosis patients, tuberculosis patients with age $\geq 50$ years and those having extra pulmonary tuberculosis patients should be screened for diabetes mellitus.

Keywords: diabetes mellitus, tuberculosis, pre-diabetes mellitus

\section{Background}

Globally, a number of people who live with diabetes mellitus (DM) are about 451 million and this number is estimated to be 693 million by $2045 .{ }^{1}$ In Africa, about 16 million people have diabetes mellitus and there are about $69.2 \%$ undiagnosed diabetes mellitus. In the region, it is projected to be 41 million by $2045 .^{2}$

Diabetes mellitus alters specific cytokines, which have roles in tuberculosis (TB) protection and it is a risk factor for the development of active tuberculosis . The impairment of immune response in patients with diabetes mellitus results in either primary infection with tuberculosis or reactivation of latent tuberculosis. ${ }^{3}$ 
In Sub-Saharan Africa, infectious diseases, including tuberculosis are likely to increase in the region due to diabetes mellitus. ${ }^{4}$ Diabetes mellitus increases the risk of tuberculosisdevelopment three-fold. ${ }^{5}$ Bi-directional screenings of tuberculosis and diabetes mellitus ranges $1.7-36 \%$ and $1.9-35 \%$ respectively. ${ }^{6}$ Another systematic review indicated that the prevalence of $\mathrm{DM}$ in $\mathrm{TB}$ patients ranged from $1.9 \%$ to $45 \%$. $^{7}$ Several studies show that diabetes mellitus increases the risk of tuberculosis. ${ }^{8-12}$

A systematic review of Asian countries showed that diabetes mellitus prevalence among tuberculosis patients was between $5 \%$ to $50 \%$, whereas tuberculosis prevalence among diabetes mellitus patients was 1.8-9.5 times higher than the general population in developing Asian countries. $^{13}$

A systematic review conducted on diabetes mellitus and tuberculosis comorbidity in most low and middle income countries (LMICs) varies from $1.8 \%$ to $45 \%$, with the majority found between $10 \%$ and $30 \% .{ }^{14}$ Factors associated with comorbidity of diabetes mellitus and tuberculosis were age, sex, being pulmonary tuberculosis, being hypertensive, family history of diabetes mellitus, alcohol consumption and residence.

Globally, the number of patients with diabetes mellitus comorbidity is higher than the number of patients with tuberculosis and human immunodeficiency virus coinfection. $^{15}$ Considering this, the World Health Organization and the International Union Against Tuberculosis and Lung Disease recommend bi-directional screening of the two diseases. ${ }^{16}$

Several studies indicated that diabetes mellitus and tuberculosis comorbidity results in treatment failure, prolongs sputum positivity, relapse and risk of developing multi-drug resistant tuberculosis and high risk of death. ${ }^{17-21}$ Therefore, the present study carried out to assess the prevalence and factors associated with diabetes mellitus and tuberculosis comorbidity in the study area.

\section{Methods}

\section{Study Design, Area and Period}

An institutional-based cross-sectional study was conducted from March 30, 2019 to April 30, 2019 in Bale Zone Health Institutions, Southeast Ethiopia. Bale Zone is located in Southeastern Ethiopia. The capital city of the Zone (Robe) is $430 \mathrm{Km}$ far from Addis Ababa, capital city of Ethiopia.

\section{Source Population, Sample Size and Sampling Technique}

The source population was adult tuberculosis patients in the selected Health Institutions. The sample size was calculated using single population proportion formula. The sample size was calculated using single proportion formula with the assumption of $95 \% \mathrm{CI}$ and a $5 \%$ margin of error and $15.8 \%$ prevalence of diabetes mellitus among tuberculosis patients at a St. Peter hospital in Addis Ababa. ${ }^{34}$ Then, the calculated sample size became 204 and using a design effect of 1.5 and with addition of five percent non-response rate and the final sample size became 321.

$$
\mathrm{N}=\frac{z^{2}}{d^{2}} \mathrm{p} \quad(1-\mathrm{P})=\frac{1.96^{2}}{0.05^{2}} * 0.158(1-0.158)=204 * 1.5=306
$$
with the addition of five percent non-response rate it became 321 .

The sampling technique was using a lottery method. Among Bale zone health institutions fifteen health centers and two hospitals were selected using the lottery method. Then for each selected health institutions sample size was allocated proportionally. The simple random sampling technique was used to select the study participants using tuberculosis registration book as the sampling frame.

\section{Data Collection Tools and Procedure}

The data were collected using a structured questionnaire adapted from WHO STEPwise instrument and registration review. WHO STEPwise instrument has three sequential steps. First information regarding socio-demographic and behavioral factors was collected using a questionnaire adapted from the WHO STEPwise instrument. Then, after anthropometric measurement and finally, blood glucose level measurement was done. The patients, height were measured with their removal of foot wear and head gear and recorded in centimeter. Weight of the patient was also measured with removal of foot wear and recorded in kilograms. Finally, all patients diagnosed as having active TB was screened for DM through measurement of fasting blood glucose (FBG) level using glucometer. Diabetes mellitus was diagnosed if the fasting blood glucose level (FBG) level was $\geq 126 \mathrm{mg} / \mathrm{dl}$ at 2 different time points.

\section{Data Quality Issues}

The questionnaire was first translated from English to Afan Oromo (local language) and then retranslated to English language. Data collectors were fluent speakers of Afan Oromo (local language) and Amharic. Training was 
given for data collectors and supervisor for two days on the objective, relevance of the study and confidentiality of information. Data collection tools were pretested on $5 \%$ of the study subject out of the selected Health facility.

\section{Data Processing and Analysis}

The questionnaire was checked, cleaned, coded and entered to Epidata 3.0.2 and analyzed by using SPSS version 20. A binary logistic regression model was primarily used to see the association of independent variables with diabetes mellitus and tuberculosis comorbidity. Variables that had an association with diabetes mellitus and tuberculosis comorbidity (at $p$ value of less than 0.25 ) in bi-variable logistic regression were entered in to the multivariable logistic regression model to control the effects of confounders.

Finally, the variables that had significant association were identified by calculating odds ratio, with $95 \%$ confidence interval, and p- value less than 0.05 was used to declare statistical significance.

\section{Results}

\section{Socio-Demographic Characteristics of} Tuberculosis Patients on Follow-Up at Bale Zone Health Institutions, Southeast

\section{Ethiopia, $2019(\mathrm{~N}=316)$}

In this study, tuberculosis patients who were on directly observed treatment among health institutions of Bale zone participated. The response rate of the study was 316 (98.4\%). Among the study participants, 172 (52.5\%) were males. The mean age of the study participants was $32.7 \pm 14.69$ years. The majority of the study participants were urban dwellers 199 (63\%) and most of study participants $188(59.5 \%)$ were in the age group of $25-44$ years (Table 1).

\section{Prevalence of Diabetes Mellitus and Tuberculosis Comorbidity Among} Tuberculosis Patients at Bale Zone Health Institutions, Southeast Ethiopia, 2019 $(\mathrm{N}=3 \mid 6)$

In this study, the prevalence of diabetes mellitus and tuberculosis comorbidity was $5.1 \%(2.7-7.5 \%)$. Diabetes mellitus and tuberculosis comorbidity distribution among sex, age category and type of tuberculosis (Figure 1).
Table I Socio-Demographic Characteristics of Tuberculosis Patients on Follow-Up at Bale Zone Health Institutions, Southeast Ethiopia, $2019(\mathrm{~N}=316)$

\begin{tabular}{|l|l|l|}
\hline Characteristics & Number & Percent \\
\hline Age & & \\
$\leq 24$ & 78 & $24.7 \%$ \\
$25-44$ & 188 & $59.5 \%$ \\
$45-64$ & 41 & $13 \%$ \\
$\geq 65$ & 9 & $28 \%$ \\
\hline Sex & & \\
Male & 172 & $54.4 \%$ \\
Female & 144 & $45.6 \%$ \\
\hline Residence & & \\
Rural & 117 & $37 \%$ \\
Urban & 199 & $63 \%$ \\
\hline Education & & \\
No formal education & 79 & $25 \%$ \\
Primary & 144 & $45.6 \%$ \\
Secondary & 37 & $11.7 \%$ \\
Diploma graduate & 6 & $1.9 \%$ \\
Degree and above & 50 & $15.8 \%$ \\
\hline Marital status & & \\
Single & 82 & $25.9 \%$ \\
Married & 220 & $1.6 \%$ \\
Widowed & 9 & $11.6 \%$ \\
Divorced & 5 & \\
\hline Occupation & $37.9 \%$ \\
Farmer & 99 & \\
House wife & & \\
Government employee & & \\
Non-government employee & & \\
Daily laborer & & \\
\hline
\end{tabular}

\section{Health and Behavioral Factors Among} Tuberculosis Patients at Bale Zone Health Institutions, Southeast Ethiopia, 2019 $(\mathrm{N}=316)$

In this study, about $21(6.6 \%)$ of study participants consumed alcohol within the past 12 months. Regarding tuberculosis among the study participants pulmonary tuberculosis and extra tuberculosis patients were 233 (73.7) and $83(26.3 \%)$ respectively (Table 2$)$.

Factors Associated with Diabetes Mellitus and Tuberculosis CoMorbidity

Both bi-variable and multiple logistic regressions were carried out. Variables with $p$ value of $\leq 0.25$ were used 


\section{DM-TB co-morbidity}

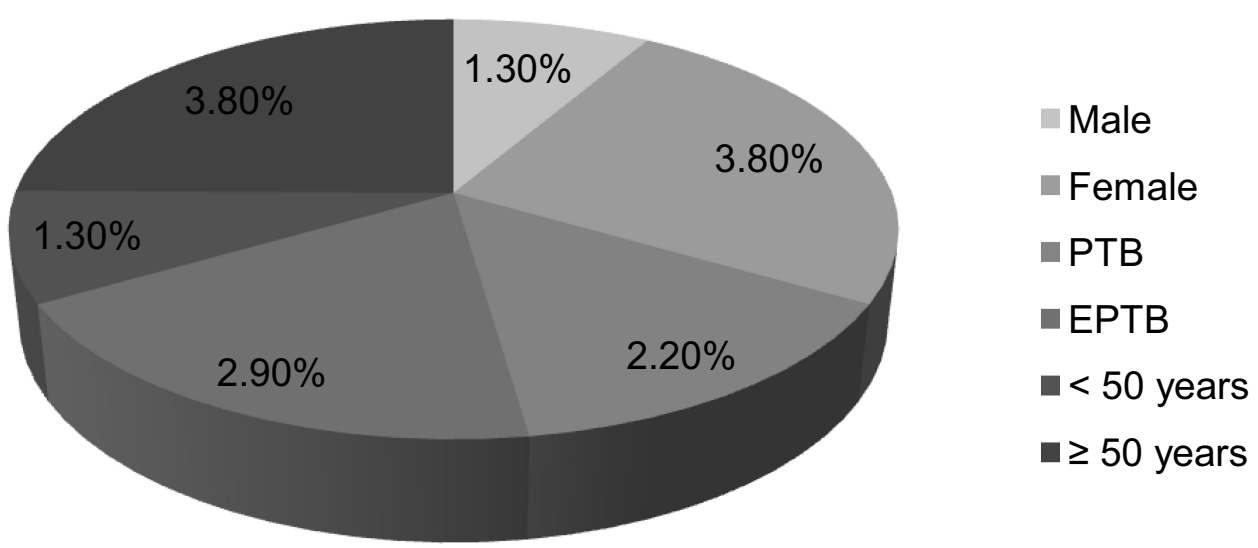

Figure I Diabetes mellitus and tuberculosis comorbidity among sex, age category and type of tuberculosis among study participants of Bale zone health institutions, Southeast Ethiopia $(n=3 \mid 6)$.

as candidates for multiple logistic regressions. According, variables that were used in bi-variable logistic regressions were age, sex, residence, type of tuberculosis and education status. However, in multiple logistic regressions having extra pulmonary tuberculosis, being females and age equal to or older than fifty years were factors associated with diabetes mellitus and tuberculosis comorbidity (Table 3).

\section{Discussion}

The present study was carried out among 316 adult tuberculosis patients who were on follow-up at selected Health Institutions of Bale Zone. The response rate was 97.8\%. Diabetes mellitus and tuberculosis has bi-directional association. Diabetes mellitus can cause tuberculosis due hyperglycemia damage cytokines that have roles in tuberculosis prevention.

In the present study, the prevalence of diabetes mellitus and tuberculosis comorbidity was 16 (5.1\%). This finding was consistent with study conducted in Pakistan $(5.69 \%),{ }^{22,23}$ Gujarat in India $(6.5 \%),{ }^{23}$ Nigeria $(5.5 \%)^{24}$ and Lusaka in Zambia (5\%). ${ }^{25}$ The finding of this study was higher compared to studies conducted in Sri Lanka $(2 \%),{ }^{26}$ Mozambique (1\%) ${ }^{27}$ and Egypt $(2.09 \%) .{ }^{28}$ The possible reason might be due study area and also might be due methods used to screen for diabetes mellitus. Screening of diabetes mellitus using different methods can affect the prevalence. In the present study diabetes mellitus were screened using capillary blood. This might increase the prevalence as it might be affected with stress.

However, the finding of this study was lower compared to study conducted in Nepal $(9.1 \%),{ }^{29}$ Vietnam $(13.7 \%),{ }^{30}$ in Madhya Pradesh in India (15.4\%), ${ }^{31}$ tribal South India $(15 \%),{ }^{32}$ in Bhopal in India, ${ }^{33}$ Kerala in India $(24 \%),{ }^{34}$ Beijing in China (16.2\%), ${ }^{35}$ Uganda (8.5\%), ${ }^{36}$ Sri Lanka $(22.5 \%)^{37}$ and Lagos in Nigeria (12.3\%). ${ }^{38}$ This difference of prevalence compared to these countries might be due to socio-demographic difference and might be also due to socio-economic difference.

The prevalence of this study was also lower compared to studies conducted in St. Peter hospital, Addis Ababa $(15.8 \%),{ }^{25}$ in Gondar, Gondar teaching and referral hospital (8.5\%), ${ }^{24}$ and in Amhara Region (8.3\%). ${ }^{23}$ The possible reason might be due time of screening tuberculosis patients for diabetes mellitus. Screening of tuberculosis patients for diabetes mellitus during their presentation might be hyperglycemic due to severity of illness. Another possible reason might be also due to study areas. Since the prevalence of diabetes mellitus has difference between urban and rural. Sample size might be also a possible reason for the discrepancy of the prevalence.

Factors associated with diabetes mellitus and tuberculosis co-morbidity in the present study both in binary logistic regressions and multiple regressions were being female, age equal to or older than 50 years, and having extra pulmonary tuberculosis. Accordingly, the odds of being diabetes mellitus and tuberculosis co-morbidity 
Table 2 Health and Behavioral Characteristics Among Tuberculosis Patients at Bale Zone Health Institutions, Southeast Ethiopia, $2019(\mathrm{~N}=316)$

\begin{tabular}{|c|c|c|}
\hline Characteristics & Number & Percentage \\
\hline \multicolumn{3}{|l|}{ Family history of Diabetes mellitus } \\
\hline Yes & I & $0.3 \%$ \\
\hline No & 315 & $99.7 \%$ \\
\hline \multicolumn{3}{|l|}{ Previously known hypertension } \\
\hline Yes & 2 & $0.6 \%$ \\
\hline No & 314 & $99.4 \%$ \\
\hline \multicolumn{3}{|l|}{ TB treatment duration } \\
\hline$\leq 2$ months & 117 & $37 \%$ \\
\hline$>2$ months & 199 & $63 \%$ \\
\hline \multicolumn{3}{|l|}{ Type of TB } \\
\hline Pulmonary TB & 233 & $73.7 \%$ \\
\hline Extra pulmonary TB & 83 & $26.3 \%$ \\
\hline \multicolumn{3}{|l|}{ TB-HIV co-infection } \\
\hline Yes & 12 & $3.8 \%$ \\
\hline No & 304 & $96.2 \%$ \\
\hline \multicolumn{3}{|l|}{ Physical activity } \\
\hline Yes & 38 & $12 \%$ \\
\hline No & 278 & $88 \%$ \\
\hline \multicolumn{3}{|l|}{ Alcohol consumption } \\
\hline Yes & 21 & $6.6 \%$ \\
\hline No & 295 & $93.4 \%$ \\
\hline
\end{tabular}

were about four times more likely among tuberculosis patients with age of equal to or older than 50 years patients compared to those with age of less than 50 years old tuberculosis patients (AOR=3.98, CI: 1.11-14.3). The possible reason might be due lack of physical activity during the age of old age.

This finding was in line with study conducted in Pondicherry in India and in Nepal. ${ }^{37,39}$ On the other hand, being female was also significantly associated with diabetes mellitus and tuberculosis comorbidity.

The odds of diabetes mellitus and tuberculosis comorbidity among tuberculosis were about four times more likely compared to male tuberculosis patients $(\mathrm{AOR}=3.7$, CI: 1.14-12.16). The possible reason might be due gestational diabetes mellitus during her previous pregnancy and this might be a risk factor for developing diabetes mellitus.

This finding was comparable with study conducted in Egypt $^{28}$ and Amhara Region. ${ }^{23}$ However, the present study was inconsistent with study conducted in Bhopal India and Italy. In Bhopal and Italy being males were significantly associated with diabetes mellitus among tuberculosis patients. This inconsistency might be due to the difference of behavioral factors across different regions. In some regions male and female behavioral factors are different. This difference might result different association regarding diabetes mellitus and sex.

Table 3 Factors Associated with Diabetes Mellitus and Tuberculosis Comorbidity Using Both Bi-Variable and Multiple Logistic Regressions Analysis Among Tuberculosis Patients at Bale Zone Health Institutions, Southeast Ethiopia, 2019 (N=316)

\begin{tabular}{|c|c|c|c|c|c|}
\hline \multirow[t]{2}{*}{ Variables } & \multicolumn{2}{|c|}{ Diabetes Mellitus } & \multirow[t]{2}{*}{ 95\% COR } & \multirow[t]{2}{*}{ 95\% AOR } & \multirow[t]{2}{*}{$P$ value } \\
\hline & Yes & No & & & \\
\hline \multicolumn{6}{|l|}{ Sex } \\
\hline Male & 4 & 168 & I & & \\
\hline Female & 12 & 132 & $3.8(1.2,12.3)$ & $3.73(1.14,12.16)$ & $0.029 *$ \\
\hline \multicolumn{6}{|l|}{ Age (years) } \\
\hline$<50$ & 4 & 277 & I & & \\
\hline$\geq 50$ & 12 & 23 & $4.03(1.13,8.58)$ & $3.98(1.11,14.3)$ & $0.034^{*}$ \\
\hline \multicolumn{6}{|l|}{ Education status } \\
\hline No formal education & 7 & 73 & 1 & & \\
\hline Formal education & 9 & 227 & $0.4 I(0.15, I .15)$ & $0.64(0.21,1.97)$ & 0.44 \\
\hline \multicolumn{6}{|l|}{ Residence } \\
\hline Urban & 7 & 192 & I & & \\
\hline Rural & 9 & 108 & $2.29(0.83,6.31)$ & $2.03(0.68,6.01)$ & 0.44 \\
\hline \multicolumn{6}{|l|}{ Type of TB } \\
\hline РTB & 7 & 226 & I & & \\
\hline EPTB & 9 & 74 & & $3.31(1.16,9.44)$ & $0.025^{*}$ \\
\hline
\end{tabular}

Note: *p value $<0.05$. 
Having extra pulmonary tuberculosis was also associated with diabetes mellitus and tuberculosis comorbidity. In the present study the odds of being diabetes mellitus and tuberculosis co-morbidity among extra pulmonary tuberculosis were about three times more likely compared to pulmonary tuberculosis patients $(\mathrm{AOR}=3.31$, CI: $1.16-$ 9.44). This finding was consistent with a study conducted in United Kingdom. ${ }^{39}$ However, the present study was inconsistent with study conducted in Bhopal in India and in South East of Amhara Region. ${ }^{33,40}$ The possible reason for this might be due extra tuberculosis can affect pancreas and this can result in developing diabetes mellitus.

\section{Conclusion}

The prevalence of diabetes mellitus and tuberculosis comorbidity among adult tuberculosis patients in the present study was high. In the present study age with equal to or older than fifty years, having extra pulmonary tuberculosis and being females were significantly associated with diabetes mellitus and tuberculosis comorbidity.

\section{Strength and Limitation of the Study}

The strength of the study was that patients from both health centers and hospitals were included and its limitation was using capillary blood to screen for diabetes mellitus. Therefore, it was better if hemoglobin A1c used to screen for diabetes mellitus.

\section{Abbreviations}

AOR, adjusted odds ratio; COR, crude odds ratio; DM, diabetes mellitus; LMIC, low and middle income countries; TB, tuberculosis; WHO, World Health Organization.

\section{Data Sharing Statement}

The data sets of the current study were available from the corresponding author on reasonable request and these data sets will be deidentified.

\section{Ethical Approval and Consent to Participate}

This study was conducted in accordance with Declaration of Helsinki. Ethical clearance was obtained from Jimma University, Institutional Review Board. Written consent was obtained from the study participants after explaining the purpose of the study and the benefits. Respondents were interviewed voluntarily and confidentiality was assured.

\section{Acknowledgment}

We would like to thank study participants, data collectors, supervisors and Bale Zone Health Office.

\section{Author Contributions}

All authors made a significant contribution to the work reported, whether that is in the conception, study design, execution, acquisition of data, analysis and interpretation, or in all these areas; took part in drafting, revising or critically reviewing the article; gave final approval of the version to be published; have agreed on the journal to which the article has been submitted; and agree to be accountable for all aspects of the work.

\section{Funding}

Funding was obtained from Jimma University for this study.

\section{Disclosure}

The authors have no conflicts of interest.

\section{References}

1. Cho N, Shaw J, Karuranga S, et al. IDF diabetes atlas: global estimates of diabetes prevalence for 2017 and projections for 2045 . Diabetes Res Clin Pract. 2018;138:271-281. doi:10.1016/j. diabres.2018.02.023

2. IDF. Diabetes Atlas Eighth Edition 2017.

3. Kumar Nathella P, Babu S. Influence of diabetes mellitus on immunity to human tuberculosis. Immunology. 2017;152(1):13-24.

4. Hall V, Thomsen RW, Henriksen O, Lohse N. Diabetes in Sub Saharan Africa 1999-2011: epidemiology and public health implications. A systematic review. BMC Public Health. 2011;11(1):564. doi:10.1186/1471-2458-11-564

5. Jeon CY, Murray MB, Williams B. Diabetes mellitus increases the risk of active tuberculosis: a systematic review of 13 observational studies. PLoS Med. 2008;5(7):e152. doi:10.1371/journal.pmed.0050152

6. Jeon CY, Harries AD, Baker MA, et al. Bi-directional screening for tuberculosis and diabetes: a systematic review. Trop Med Int Health. 2010;15(11):1300-1314. doi:10.1111/j.1365-3156.2010.02632.x

7. Workneh MH, Bjune GA, Yimer SA, Wilkinson KA. Prevalence and associated factors of tuberculosis and diabetes mellitus comorbidity: a systematic review. PLoS One. 2017;12(4):e0175925. doi:10.1371/ journal.pone. 0175925

8. Baker MA, Harries AD, Jeon CY, et al. The impact of diabetes on tuberculosis treatment outcomes: a systematic review. BMC Med. 2011;9(1):81. doi:10.1186/1741-7015-9-81

9. Viswanathan V, Kumpatla S, Aravindalochanan V, et al. Prevalence of diabetes and pre-diabetes and associated risk factors among tuberculosis patients in India. PLoS One. 2012;7(7):e41367. doi:10.1371/ journal.pone. 0041367

10. Balakrishnan S, Vijayan S, Nair S, et al. High diabetes prevalence among tuberculosis cases in Kerala, India. PLoS One. 2012;7(10): e46502. doi:10.1371/journal.pone.0046502

11. Restrepo BI, Camerlin AJ, Rahbar MH, et al. Cross-sectional assessment reveals high diabetes prevalence among newly-diagnosed tuberculosis cases. Bull World Health Organ. 2011;89:352-359. doi:10. 2471/BLT.10.085738 
12. Al-Rifai RH, Pearson F, Critchley JA, Abu-Raddad LJ, Palazón-Bru A. Association between diabetes mellitus and active tuberculosis: a systematic review and meta-analysis. PLoS One. 2017;12(11): e0187967. doi:10.1371/journal.pone.0187967

13. Zheng $\mathrm{C}, \mathrm{Hu} \mathrm{M}$, Gao F. Diabetes and pulmonary tuberculosis: a global overview with special focus on the situation in Asian countries with high TB-DM burden. Glob Health Action. 2017;10(1):1264702. doi:10.1080/16549716.2016.1264702

14. McMurry HS, Mendenhall E, Rajendrakumar A, Nambiar L, Satyanarayana S, Shivashankar R. Coprevalence of type 2 diabetes mellitus and tuberculosis in low-income and middle-income countries: a systematic review. Diabetes Metab Res Rev. 2019;35(1): e3066.

15. Wagnew F, Eshetie S, Alebel A, Dessie G, Tesema C, Abajobir AA. Meta-analysis of the prevalence of tuberculosis in diabetic patients and its association with cigarette smoking in African and Asian countries. BMC Res Notes. 2018;11(1):298. doi:10.1186/s13104018-3390-x

16. WHO. Collaborative Framework for Care and Control of Tuberculosis and Diabetes. Geneva: World Health Organization; 2011.

17. Shariff NM, Safian N. Diabetes mellitus and its influence on sputum smear positivity at the 2nd month of treatment among pulmonary tuberculosis patients in Kuala Lumpur, Malaysia: a case control study. Int J Mycobacteriol. 2015;4(4):323-329. doi:10.1016/j.ijmyco. 2015.09.003

18. Pérez-Navarro LM, Fuentes-Domínguez FJ, Zenteno-Cuevas R. Type 2 diabetes mellitus and its influence in the development of multidrug resistance tuberculosis in patients from southeastern Mexico. $J$ Diabetes Complications. 2015;29(1):77-82. doi:10.1016/j.jdiacomp. 2014.09.007

19. Dooley KE, Tang T, Golub JE, Dorman SE, Cronin W. Impact of diabetes mellitus on treatment outcomes of patients with active tuberculosis. Am J Trop Med Hyg. 2009;80(4):634-639. doi:10. 4269/ajtmh.2009.80.634

20. Kapur A, Harries AD. The double burden of diabetes and tuberculosis-public health implications. Diabetes Res Clin Pract. 2013;101 (1):10-19. doi:10.1016/j.diabres.2012.12.001

21. Sullivan T, Amor YB. The co-management of tuberculosis and diabetes: challenges and opportunities in the developing world. PLoS Med. 2012;9(7):e1001269. doi:10.1371/journal.pmed.1001269

22. Usmani RA, Nasir MI, Wazir S, Pervaiz Z, Zahra T, Akhtar M. Diabetes mellitus among tuberculosis patients in a tertiary care hospital of Lahore. J Ayub Med Coll Abbottabad. 2014;26(1):61-63.

23. Dave P, Shah A, Chauhan M, et al. Screening patients with tuberculosis for diabetes mellitus in Gujarat, India. Public Health Action. 2013;3(1):29-33. doi:10.5588/pha.13.0027

24. Ekeke N, Ukwaja KN, Chukwu JN, et al. Screening for diabetes mellitus among tuberculosis patients in Southern Nigeria: a multicentre implementation study under programme settings. Sci Rep. 2017;7:44205. doi:10.1038/srep44205

25. Fwoloshi S, Hachaambwa LM. Screening for diabetes mellitus among tuberculosis patients: findings from a study at a Tertiary Hospital in Lusaka, Zambia. Can J Infect Dis Med Microbiol. 2018;2018:5.
26. Rajapakshe W, Isaakidis P, Sagili K, et al. Screening patients with tuberculosis for diabetes mellitus in Ampara, Sri Lanka. Public Health Action. 2015;5(2):150-152. doi:10.5588/pha.15.0006

27. Pizzol D, Di Gennaro F, Chhaganlal KD, et al. Prevalence of diabetes mellitus in newly diagnosed pulmonary tuberculosis in Beira, Mozambique. Afr Health Sci. 2017;17(3):773-779. doi:10.4314/ahs. v17i3.20

28. Gadallah M, Amin W, Fawzy M, Mokhtar A, Mohsen A. Screening for diabetes among tuberculosis patients: a nationwide populationbased study in Egypt. Afr Health Sci. 2018;18(4):884-890. doi:10. 4314/ahs.v18i4.6

29. Thapa B, Paudel R, Thapa P, Shrestha A, Poudyal A. Prevalence of diabetes among tuberculosis patients and associated risk factors in Kathmandu valley. STAC. 2015;12(2):20-27. doi:10.3126/saarctb. v12i2.15951

30. Hoa N, Phuc P, Hien N, et al. Prevalence and associated factors of diabetes mellitus among tuberculosis patients in Hanoi, Vietnam. BMC Infect Dis. 2018;18(1):603. doi:10.1186/s12879-018-3519-5

31. Nagar V, Gour D, Arutagi V, et al. A study to assess the blood glucose level among diagnosed cases of tuberculosis registered at a tuberculosis unit of Bhopal city, Madhya Pradesh, India. Int J Med Sci Public Health. 2015;4(2):245-249. doi:10.5455/ijmsph.2015.22 10201456

32. Achanta S, Tekumalla R, Jaju J, et al. Screening tuberculosis patients for diabetes in a tribal area in South India. Public Health Action. 2013;3(1):43-47. doi:10.5588/pha.13.0033

33. Nagar V, Prasad P, Gour D, Singh AR, Pal D. Screening for diabetes among tuberculosis patients registered under revised national tuberculosis control program, Bhopal, India. J Family Med Prim Care. 2018;7(6):1401. doi:10.4103/jfmpc.jfmpc_14_18

34. Nandakumar K, Duraisamy K, Balakrishnan S, et al. Outcome of tuberculosis treatment in patients with diabetes mellitus treated in the revised national tuberculosis control programme in Malappuram District, Kerala, India. PLoS One. 2013;8(10):e76275. doi:10.1371/ journal.pone.0076275

35. Hongguang C, Min L, Shiwen J, et al. Impact of diabetes on clinical presentation and treatment outcome of pulmonary tuberculosis in Beijing. Epidemiol Infect. 2015;143(1):150-156.

36. Kibirige D, Ssekitoleko R, Mutebi E, Worodria W. Overt diabetes mellitus among newly diagnosed Ugandan tuberculosis patients: a cross sectional study. BMC Infect Dis. 2013;13(1):122. doi:10.1186/ 1471-2334-13-122

37. Umakanth M, Rishikesavan S. Prevalence of diabetes mellitus among tuberculosis patient in Batticaloa district, Sri Lanka. Prevalence. 2017;2(2).

38. Ogbera AO, Kapur A, Abdur-Razzaq H, et al. Clinical profile of diabetes mellitus in tuberculosis. BMJ Open Diabetes Res Care. 2015;3(1):e000112. doi:10.1136/bmjdrc-2015-000112

39. Pearson F, Huangfu P, McNally R, Pearce M, Unwin N, Critchley JA. Tuberculosis and diabetes: bidirectional association in a UK primary care data set. J Epidemiol Community Health. 2019;73(2):142-147. doi:10.1136/jech-2018-211231

40. Workneh MH, Bjune GA, Yimer SA, Pai M. Prevalence and associated factors of diabetes mellitus among tuberculosis patients in South-Eastern Amhara Region, Ethiopia: a cross sectional study. PLoS One. 2016;11(1):e0147621. doi:10.1371/journal.pone.0147621 


\section{Publish your work in this journal}

Diabetes, Metabolic Syndrome and Obesity: Targets and Therapy is an international, peer-reviewed open-access journal committed to the rapid publication of the latest laboratory and clinical findings in the fields of diabetes, metabolic syndrome and obesity research. Original research, review, case reports, hypothesis formation, expert opinion and commentaries are all considered for publication. The manuscript management system is completely online and includes a very quick and fair peer-review system, which is all easy to use. Visit http://www.dovepress.com/testimonials.php to read real quotes from published authors. 